\title{
Statistical Analysis of the Flexural Strength of Free-Standing Flame-Sprayed Alumina Coatings Prior and After Thermal Shock
}

\author{
Marc Neumann $^{1} \cdot$ Patrick Gehre $^{1} \cdot$ Jana Hubálková $^{1} \cdot$ Henry Zielke $^{2} \cdot$ \\ Martin Abendroth ${ }^{2} \cdot$ Christos G. Aneziris ${ }^{1}$
}

Submitted: 30 June 2020/in revised form: 12 October 2020/ Accepted: 13 October 2020

(C) The Author(s) 2020, corrected publication 2021

\begin{abstract}
The impact of thermal shock upon the scatter of flexural strength data of free-standing thin flame-sprayed $\mathrm{Al}_{2} \mathrm{O}_{3}$ coatings was examined. As published in the literature, thermally sprayed ceramic systems exhibit superior thermal shock resistance and against this background, the statistical evaluation of strength data prior and after the thermal shock was intensified. Thus, the Weibull parameters $m$ and $\sigma_{0}$ were compared before and after thermal shock from $1000{ }^{\circ} \mathrm{C}$ to room temperature. The flexural strength was determined utilising the ball-on-three-balls method. Although the general scale of the Weibull modulus $m$ was rather low $(<6)$, considerable differences were shown after thermal shocking as the Weibull modulus decreased by a factor of about 3 .
\end{abstract}

Keywords alumina - flexural strength · statistical analysis . thermal shock $\cdot$ thermal spraying

\section{Introduction}

Nowadays, thermally sprayed ceramic coatings gained raised attention. Potential applications range from electrical components to high-temperature applications such as metal melt filtration. Their property profile is given through their unique lamellar microstructure, evincing numerous

Marc Neumann

marc.neumann@ikgb.tu-freiberg.de

1 Institute of Ceramic, Glass and Construction Materials, TU Bergakademie Freiberg, 09599 Freiberg, Germany

2 Institute of Mechanics and Fluid Dynamics, TU Bergakademie Freiberg, 09599 Freiberg, Germany microcracks, amorphous zones, and pores, resulting from the thermal-spray process itself (Ref 1-4).

A key property to e.g. assess mechanical handling or thermal shock performance of ceramic components is the flexural strength. Within the characterisation of strength, the scatter of strength data represents a material property, whereas the scale of strength is related to the components' geometry and size, hence, to the effectively stressed volume. Against this background, the analysis of strength data in terms of Weibull theory addresses the quantification of that scatter by the scatter parameter $m$, called Weibull modulus. Moreover, a scale parameter, the characteristic strength $\sigma_{0}$, can be derived for the investigated effective specimen volume or effective surface area, respectively (Ref 5). The estimation of both is outlined in the European Standard EN 843-5 (2006).

Through literature review, a broad overview regarding the mechanical properties of free-standing thermally sprayed (more precisely flame-sprayed) alumina is provided (Ref 6-8). Recently, fracture mechanical properties were investigated, such as fracture toughness or R-curve behaviour. When compared to sintered alumina, the fracture toughness $K_{\text {Ic }}$ was found lowered for flame-sprayed alumina (Ref 8). In agreement with that, a lowered strength was frequently reported for flame-sprayed $\mathrm{Al}_{2} \mathrm{O}_{3}$ as well, which is mainly attributed to the weakened microstructure (Ref 6-8). However, as shown by Aneziris et al. $(\operatorname{Ref} 7)$, the thermal shock performance of flame-sprayed alumina is superior compared to conventional oxidic ceramic products. By thermal shock experiments according to Hasselman (Ref 9, 10), critical temperature differences without strength degradation up to $800 \mathrm{~K}$ could be derived. In addition, a decrease in strength of about $40 \%$ only was reported for a temperature drop of about $1000 \mathrm{~K}$. However, the determination of the Weibull parameters was not 
performed after thermal shocking. Back then, the Weibull modulus $m$ prior to thermal shock amounted 4.7 (Ref 7). Key point of the presented research is the determination and comparison of the Weibull modulus $m$ and $\sigma_{0}$ before and after thermal shock. During industrial application though, e.g. as thermal barrier coatings, flame-sprayed coatings will be affected by multiple thermal shocks (Ref 11). Consequently, conception and validation of the flexural strength measurement after subjecting the coatings to a temperature difference appears highly relevant. Beyond describing the scatter and scale of the strength either prior or after thermal shock, both characteristics could be further utilised for the estimation of component lifetime under static or cyclic load, as described by Munz and Fett (Ref 5).

\section{Experimental}

All specimens were produced using commercial alumina rods (Rokide A) as feedstock and a MasterJet flame-spray gun (both from Saint-Gobain, Avignon, France). The molten alumina droplets were projected onto a graphite substrate (GM-154e, Graphite Materials, Oberasbach, Germany). Due to the differences in thermal expansion behaviour of graphite and alumina, the flame-sprayed alumina coatings detached after cooling down and could be removed from the graphite substrate without rupture. Table 1 lists the used settings for the thermal-spray process.

For ball-on-three-balls testing (B3B), discs of $0.5 \mathrm{~mm}$ in thickness and $8 \mathrm{~mm}$ in diameter were produced. This was realised by spraying onto the plane circular face of a graphite cylinder of the same diameter until the desired thickness was reached. Furthermore, thin stripes of two different sizes were prepared for four-point-bending tests (geometry I: $1.5 \times 10 \times 30 \mathrm{~mm}^{3}$ and geometry II: $1.5 \times 10 \times 45 \mathrm{~mm}^{3}$ ). Here, a side face of a graphite bar of either $10 \times 30 \mathrm{~mm}^{2}$ or $10 \times 45 \mathrm{~mm}^{2}$ was employed to set the basic specimen shape. The coating process was again terminated, as the intended coating thickness was attained. The spray distance between the torch and the graphite substrate amounted $100 \mathrm{~mm}$ in all spray trials. Both

Table 1 Fuel and feed settings for the flame-spray process $\left(\mathrm{Nm}^{3}-\right.$ standard cubic metre)

\begin{tabular}{lll}
\hline \multicolumn{1}{c}{ Parameter } & Dimension & \\
\hline Flow of $\mathrm{O}_{2}$ & $\mathrm{Nm}^{3} \mathrm{~h}^{-1}$ & 3.07 \\
Flow of $\mathrm{C}_{2} \mathrm{H}_{2}$ & $\mathrm{Nm}^{3} \mathrm{~h}^{-1}$ & 1.48 \\
Flow of pressurised air & $\mathrm{Nm}^{3} \mathrm{~h}^{-1}$ & 38.00 \\
Feed rate & $\mathrm{m} \mathrm{min}^{-1}$ & $0.06-0.07$ \\
\hline
\end{tabular}

methods of preparation hold the advantage that none of the specimens required any further preparation prior to testing. It should be noted that thermal spraying was established as a coating technology, hence predominately aims for wide coatings of thicknesses less than $1 \mathrm{~mm}$. The preparation of large free-standing components with dimensions $>1 \mathrm{~mm}$ is strongly related to the process itself and requires a delicate control of the process conditions such as spray distance and angle. Otherwise, rupture appears as consequence of e.g. temperature gradients within the component during spraying. That would represent a pretesting or pre-application selection, which is considered impermissible. To maintain the coating character of the tested specimens and to keep the moment of inertia feasible, the thicknesses of the free-standing coatings were kept below $1 \mathrm{~mm}$. In order to assess the suitability of the three geometries for statistical strength characterisation, the proportion of rejects $r$ (specimens, not possible to remove from the substrate without rupture) was considered before measuring the flexural strength. This ratio was calculated by $r=1-k / k_{\mathrm{a}}$, where $k$ is the number of usable specimens and $k_{\mathrm{a}}$ the number of spray attempts, here fixed at 15. A reject proportion of $r=1$ would thus mean that 0 specimens out of 15 spray attempts could be used, while 15 specimens out of 15 spray attempts were usable when $r=0$ applies. For $r<0.05$, a geometry was considered suitable for the estimation of the Weibull parameters. Consequently, both stripe geometries needed to be excluded from strength testing, since none of them fulfilled this condition $\left(r_{\mathrm{I}}=0.13, r_{\mathrm{II}}=0.40\right)$. In contrast, the reject proportion of the disc geometry was 0 . This resulted in two test series for evaluating $m$ and $\sigma_{0}$, OTS and 1TS with 43 specimens each, as listed in Table 2.

For thermal shock, the specimens were annealed at $1000{ }^{\circ} \mathrm{C}$ for $30 \mathrm{~min}$ before being subjected to sudden quenching in water of $20^{\circ} \mathrm{C}$ (stationary). Hence, the resulting temperature gradient $\Delta T$ amounted $980 \mathrm{~K}$. The change of water temperature was neglectable due the sheer differences between total mass of all specimens per run ( $30 \mathrm{~g}$ to $50 \mathrm{~g}$ ) and the mass of the water $(10 \mathrm{~kg})$. Since a stationary water bath was used, the bath depth was set to $10 \mathrm{~cm}$ in order to allow the specimens to sink through the water in the first moments of quenching. This was meant to minimise the impacts of local thermal insulation due to

Table 2 Test series for ball-on-three-balls testing (TS-Number of thermal shocks)

\begin{tabular}{llcc}
\hline ID & \multicolumn{1}{c}{ State } & TS & Number of Specimens \\
\hline 0TS & As sprayed & 0 & 43 \\
1TS & Thermal shock & 1 & 43 \\
\hline
\end{tabular}


bubble formation at the specimen surface, as the bubbles detached during the sinking movement. It can be noted that neither an increase in water temperature nor bubbles could be observed. The total time between leaving the furnace and reaching the bottom of the water bath amounted less than $2.5 \mathrm{~s}$.

The internal structure of the material before and after thermal shock was characterised on disc specimens by the aid of 3D-image processing through $\mathrm{x}$-ray microtomography. Such was realised in a CT-Alpha (Procon x-ray GmbH, Germany) equipped with a Dexela detector (1944 pixel $\times 1526$ pixel, type 1512, Perkin Elmer Inc.). Voxels of $9.8 \mu \mathrm{m}$ edge length after reconstruction were given, due to the sample dimensions and position in between $\mathrm{x}$-ray gun and detector.

The flexural strength was calculated from the maximum load at rupture $F_{\mathrm{c}}$, the specimen thickness $t$, and the dimensionless factor $f^{*}$, depending on Poisson's ratio $v$ as well as the ratio of specimen thickness or support radius $R_{\mathrm{a}}$ to the specimen radius $R$ :

$\sigma_{\mathrm{c}, \mathrm{B} 3 \mathrm{~B}}=\mathrm{f}^{*}\left(\frac{t}{R}, \frac{R_{\mathrm{a}}}{R}, v\right) \frac{F_{\mathrm{c}}}{t^{2}}$

The underlying thickness of the specimens was determined in the centre, near the region of the maximum flexural momentum. A further detailed description of the test method and an empirical formula for $f^{*}$ can be found in the literature (Ref 12). Some major advantages are the simple specimen geometry, the adaptivity for different specimen sizes, the tolerance against geometrical imperfections of the specimen, and a potential adaptation for elevated temperatures. In the present study, the Poisson's ratio $v$ was approximated with 0.2 , as done by Neumann et al. (Ref 8) for fracture mechanical considerations of freestanding flame-sprayed alumina. For the B3B test, the radius of the used ceramic balls (alumina) was $2.5 \mathrm{~mm}$ and the supporting radius $R_{\mathrm{a}}$ was calculated from that according to Börger et al. (Ref 12). Loading in B3B was performed with a loading rate of $0.05 \mathrm{~mm} \mathrm{m^{-1 }}$. In all bending tests, the specimen face, which represented the former contact face between substrate and coating, was subjected to tensile stresses. The strength data of both test series were statistically analysed in terms of Weibull theory according to EN 843-5 (2006), resulting in the (unbiased) Weibull modulus $m$ (scatter parameter) and the characteristic strength $\sigma_{0}$ (scale parameter). For the 0TS-series, the dependence of the strength on the specimen size was analysed following the Weibull theory, as described by Eq. 2. The derived characteristic strength of the B3B-tests was transformed according to the effective surface area for four-pointbending bars of $3 \times 5 \times 45 \mathrm{~mm}^{3}$ (as tested by Neumann et al. (Ref 8)) and for three-point-bending stripes of $0.8 \times 10 \times 40 \mathrm{~mm}^{3}$ (as tested by Aneziris et al. (Ref 7)).
The mean effective surface area $S_{\text {eff }}$ of the B3B-discs was calculated using a FEM-model with specimen diameter and mean specimen thickness (Ref 13). Thus, the surface-related characteristic strength of both other bending tests $\sigma_{\mathrm{b}}$ is given by:

$\sigma_{b}=\sigma_{0}\left(\frac{S_{e f f}}{S_{b}}\right)^{1 / m}$

In here, $\sigma_{0}$ is the characteristic strength of the corresponding test series. The effective surface area $S_{\mathrm{b}}$ of a $3 \times 5 \times 45 \mathrm{~mm}^{3}$ bar in four-point bending or a $0.8 \times 10 \times 40 \mathrm{~mm}^{3}$ stripe in three-point bending was calculated according to Quinn (Ref 14).

\section{Results and Discussion}

A first indicator for their thermal shock performance can be found as all specimens survived the quenching from $1000{ }^{\circ} \mathrm{C}$ without rupture and therefore could be tested for flexural strength. In Fig. 1, x-ray tomography scans of a disc prior (A) and post (B) thermal shock are displayed. Major cracks are indicated by arrows. From Fig. 1(a), one can see that in the as-sprayed state microcracks are visible, although difficult to visualise due to the given voxel size. Since SEM-micrographs of flame-sprayed alumina, presented in the literature, show a pronounced network of microcracks though, it is assumed that the majority of these cracks would appear smaller in extension than the resolution of the tomography scans would allow for visualisation (Ref 2). In turn, after thermal shock, next to these narrow cracks (black arrows) wider, more pronounced cracks are visible (white arrows), as shown in Fig. 1(b). Figure 1(c) showcases the lateral view of the thermal shocked specimen. In the emphasised region, it can be seen that the crack arrested within the volume. Hence, the propagation of the thermal shock-induced cracks (macrocracks) was restrained. As proposed by Aneziris et al. (Ref 7), such inhibition could be attributed to the present microcrack network. In agreement with that, pronounced R-curve behaviour could be evinced for flame-sprayed alumina, according to which the energy required for crack advance increases for a propagating crack. Reasons for the increase in crack resistance were outlined as energy consumptions due to the opening of the microcrack network and meandering of the macrocrack. In sum, such mechanisms result in a reduction in energy available for the growth of the macrocrack (Ref 8).

Figure 2 shows exemplary load-displacement diagrams for B3B-testing before (black line) and after thermal shock (grey line). Similar for both is the nonlinear part near maximum loads. It is assumed that this deviation from 

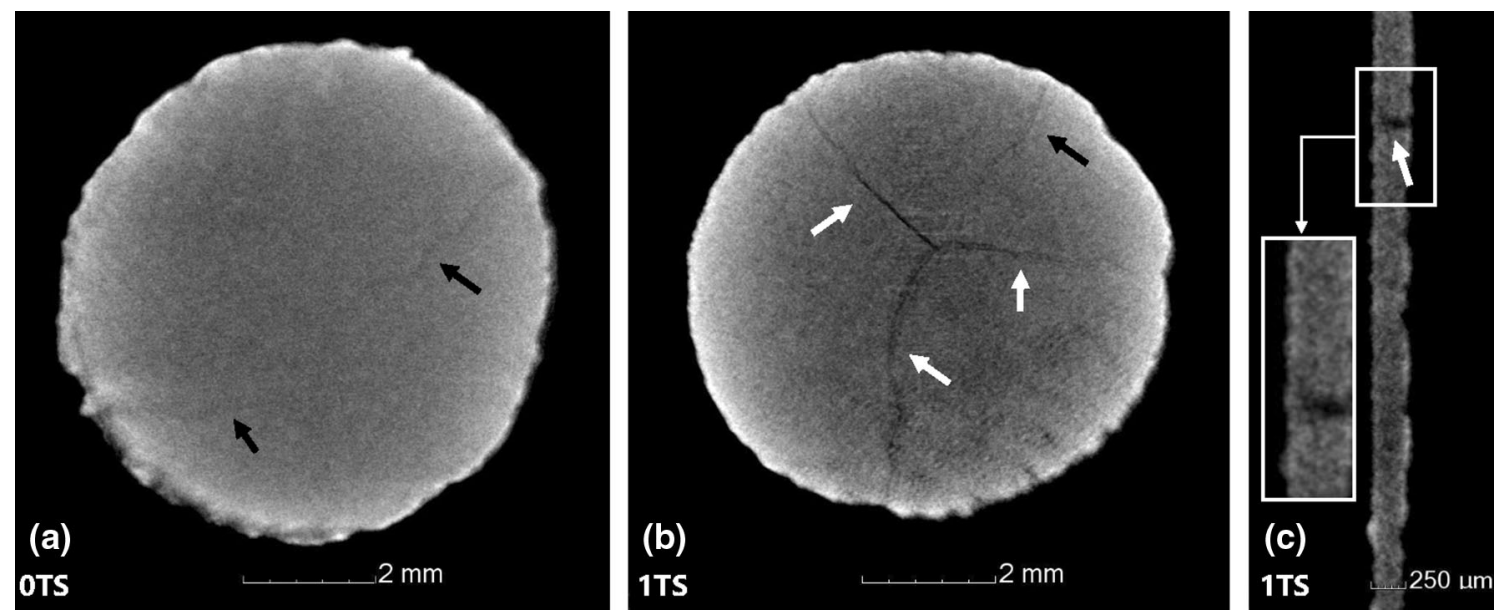

Fig. 1 X-ray tomography scans of the central plain of thermally sprayed alumina prior (a) and post (b) one thermal shock (TS) from $1000{ }^{\circ} \mathrm{C}$ to room temperature (voxel-edge length $=9.8 \mu \mathrm{m}$ ).

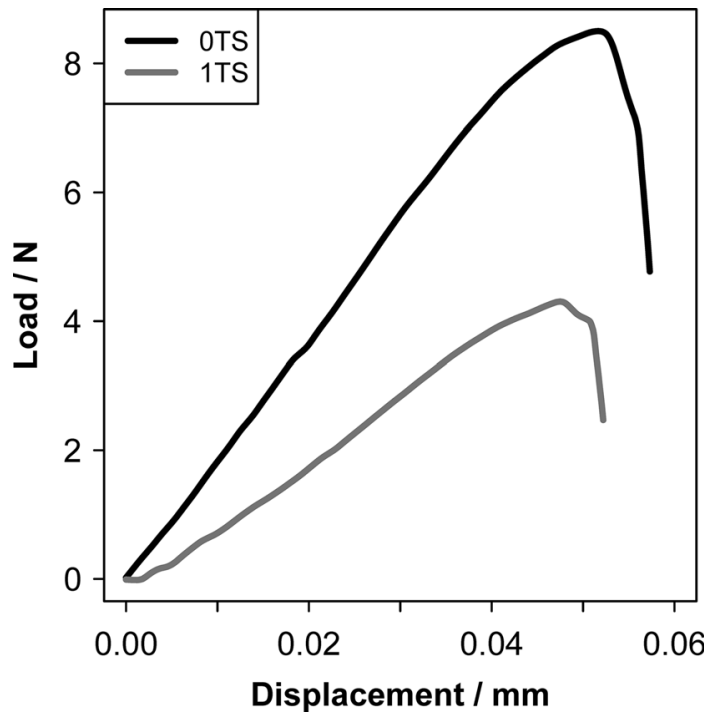

Fig. 2 Typical load versus displacement relation of the as-sprayed OTS-series (black line) and the 1TS-series after one thermal shock (TS) from $1000{ }^{\circ} \mathrm{C}$ to room temperature (grey line). The specimen thickness was similar for both selected specimens

linearity is related to subcritical crack growth of the present microcracks as a certain range of stress intensity is reached at their tips. Comparable behaviour can be seen from cyclic-loading tests of pre-notched specimens (Ref 8$)$. The apparent linear part in the beginning of the loading, however, resembles four-point-bending results, published by Neumann et al. (Ref 8) for flame-sprayed alumina of higher thicknesses. Since this linear behaviour is visible here too, the concepts of linear elastic fracture mechanics could be considered valid for thin and for bulk alumina material, prepared by flame-spray technology (Ref 8$)$.

Taking the thickness of the discs into account, this geometric characteristic appeared scattered around the
Subfigure (c) shows the lateral view of the thermal shocked specimen. Arrows indicate major cracks (black: pre-existing microcracks, white: thermal shock-induced macrocracks)

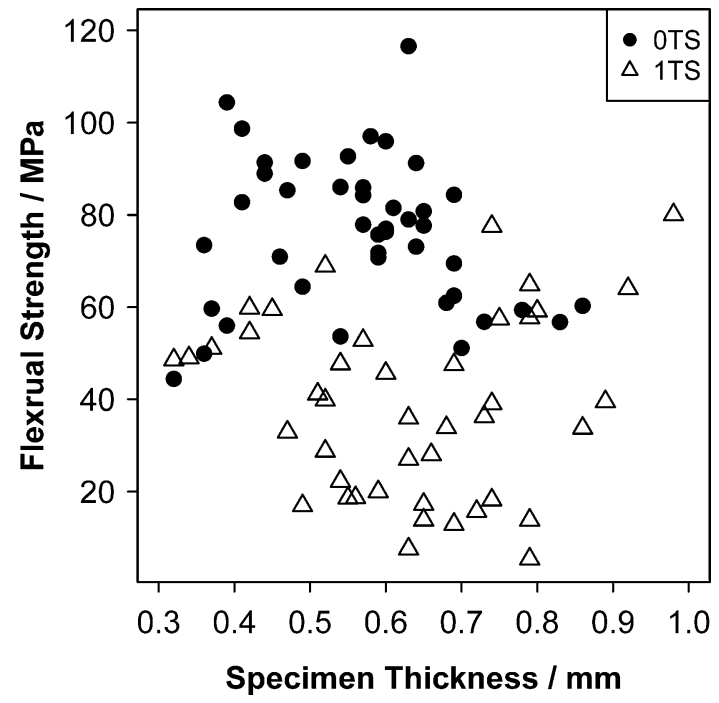

Fig. 3 Flexural strength plotted against specimen thickness for the as-sprayed 0TS-series (black dots) and the 1TS-series after one thermal shock (TS) from $1000{ }^{\circ} \mathrm{C}$ to room temperature (open triangles)

aimed $0.5 \mathrm{~mm}$ as well due to the rather chaotic flame-spray process. In Fig. 3, the measured flexural strength is plotted against the individual specimen thickness. As one can see, there is no clear trend or relation between both, neither for series 0TS, nor for series 1TS. Eventually, this hints for only minor influence of specimen thickness within the given range. It should be noted that for the lowest investigated specimen thicknesses $(0.3-0.4 \mathrm{~mm})$ individual strength values before and after thermal shock evinced about a similar scale. Again in individual cases, a comparable situation was found for thicknesses between 0.7 and $0.8 \mathrm{~mm}$. Within the central range of investigated specimen thickness $(0.4-0.7 \mathrm{~mm})$, the differences between flexural 
strength before and after thermal shock appeared more pronounced. To which extend such results could be attributed to a potential impact of thickness upon strength degradation through thermal shock or in turn to the natural scatter of the strength itself, remains an issue to be addressed in further specified investigations. For the present study though, Weibull analysis is performed covering all measurements per test series, also since the amount of data gets smaller for the aforementioned outer regions of specimen thicknesses. In that, the cumulative analysis allows for a general overview regarding sub-millimetre coatings and acts as starting point for future studies.

The resulting Weibull parameters of both test series are listed in Table 3, together with the upper and lower bound (90\% confidence band). Comparing 0TS and 1TS, a drop in the characteristic strength of about $49 \%$ is visible, which meets the expectation for a thermal shock around $1000 \mathrm{~K}$, derived from the studies of Aneziris et al. (Ref 7), as discussed above. Moreover, an obvious difference can be derived for the scatter of strength data. The Weibull modulus decreased by a factor of about 3 after thermal shocking. Compared to the Weibull modulus of hot-isostatic pressed alumina ( $m=11.8), m$ of the flame-sprayed alumina is lower by a factor of approximately 2 in the assprayed state and by a factor of about 6 after one thermal shock 1TS (Ref 15). Thus, the scatter of the strength was already large for the as-sprayed state. As the scatter of the strength is caused by the scatter of the flaw size, the Weibull modulus $m$ dropped further for the 1TS series. However, the modest strength drop as consequence of the sudden quench in water is considered remarkable, when compared to strength degradation reported for sintered polycrystalline alumina (Ref 10). The derived range of the Weibull modulus $m$ also matches the results of Aneziris et al. (Ref 7) regarding the as-sprayed state (Weibull modulus of 4.7). Other reports, addressing the variation of strength data of thermally sprayed compounds, e.g. Ostojic and Berndt (Ref 16), consider the results of tensile adhesion tests (TAT). There, a Weibull modulus of 3.3 can be found for the bond strength of thin alumina coatings, which is also of the same scale as the obtained Weibull modulus from this study. The Weibull plots of the strength data are given in detail in Fig. 4. As one can see, there are no

Table 3 Weibull modulus $m$ and characteristic strength $\sigma_{0}$, determined from 43 specimens per test series (brackets contain 90\% confidence band according to EN 843-5; TS-Number of thermal shocks)

\begin{tabular}{lccc}
\hline Test Series & TS & $m$ & $\sigma_{0}, \mathrm{MPa}$ \\
\hline 0TS & 0 & $5.48(4.46,6.77)$ & $83.46(79.38,87.80)$ \\
1TS & 1 & $1.88(1.53,2.32)$ & $42.27(36.52,48.99)$ \\
\hline
\end{tabular}

outliers since all strength values can be found within the $90 \%$ confidence bands.

Considering a theoretical strength range of $0 \mathrm{MPa}$ to $140 \mathrm{MPa}$, the probability density of flexural strength is plotted in Fig. 5 applying either of both distributions. Parameters of the Weibull distribution are the determined Weibull modulus and characteristic strength of the corresponding test series (without confidence band). Parameters of the Normal distribution are the mean and standard deviation, calculated from the 43 strength values per test series. As one can see, the deviation between Weibull and Normal distribution is rather low for 0TS, while the contrast in estimation for 1TS is more distinct, especially since for a strength of $0 \mathrm{MPa}$ a probability density $>0$ is predicted. Hence, addressing a rough estimation and scatter of the flexural strength in the as-sprayed state, arithmetic mean and standard deviation appear adequate for thin flame-sprayed alumina coatings. Comparable results are assumed to apply for flame-sprayed materials with similar melting temperatures, as their microstructure would be similar. Addressing strength degradation and scatter after thermal shock, Weibull analysis could be preferred according those findings, as the arithmetic mean would underestimate the scale of strength degradation. Hence, the thermal shock performance could be overestimated.

The recalculation of the characteristic strength for fourpoint and three-point bending was performed using the determined characteristic strength $\sigma_{0}$ for the as-sprayed state and its confidence band. Moreover, the determined Weibull modulus $m$ and its upper and lower bounds were taken into account to calculate the effective surface area $S_{\mathrm{b}}$. For the calculation of the mean effective surface area of the

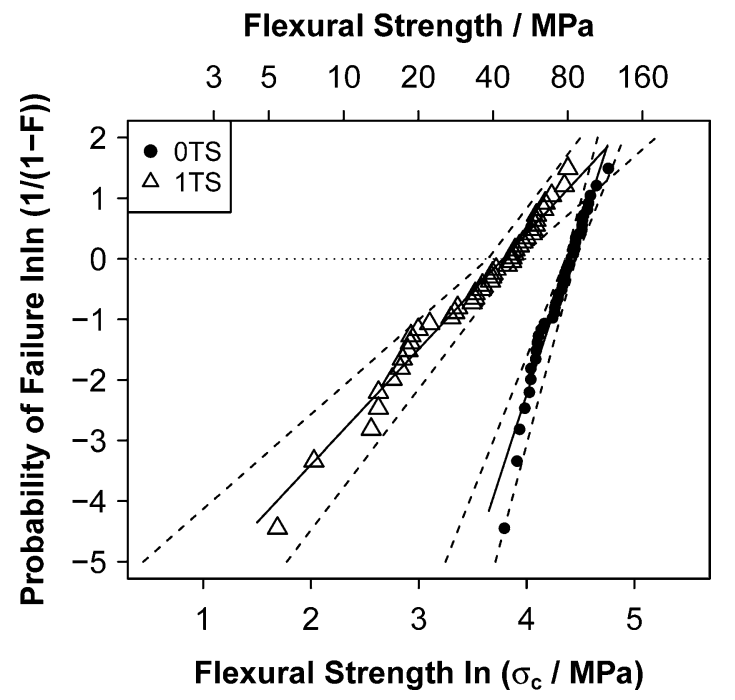

Fig. 4 Weibull plot of the strength data for the as-sprayed 0TS-series (black dots) and the 1TS-series after one thermal shock (TS) from $1000{ }^{\circ} \mathrm{C}$ to room temperature (open triangles). Solid and dashed lines represent linear fits and $90 \%$ confidence bands, respectively 
B3B-discs $S_{\text {eff }}$ only the median $m$ was implemented. The results are listed in Table 4. Clearly, the decrease in strength for an increase in effective surface is visible. The prediction of three-point-bending strength by Weibull theory is in good agreement with the scale of flexural strength, reported by Aneziris et al. (Ref 7) for specimens without any further surface treatment like polishing or cutting (flexural strength of $28.8 \mathrm{MPa}$ ). Hence, for this comparison, the estimation of the size effect by Weibull theory is considered suitable. However, the resulting values for $3 \times 5 \times 45 \mathrm{~mm}^{3}$ bars do not match the scale of flexural strength, reported for as flame-sprayed alumina in bulk form (flexural strength of 105.7 MPa) (Ref 8). It should be mentioned that back then the investigated bulk specimens had cut, thus quasi-polished surfaces. This step of specimen machining is assumed to minimise the effects of surface flaws and their contribution to the fracture process, which shifts the measured strength towards higher values than predicted by Weibull theory.

To extrapolate the observed effects in the Weibull statistics to different thermal shock temperature gradients, further tests are required. According to Hasselman (Ref 9,10 ), for polycrystalline alumina, the strength as function of the thermal history $(\Delta T)$ undergoes four different stages,

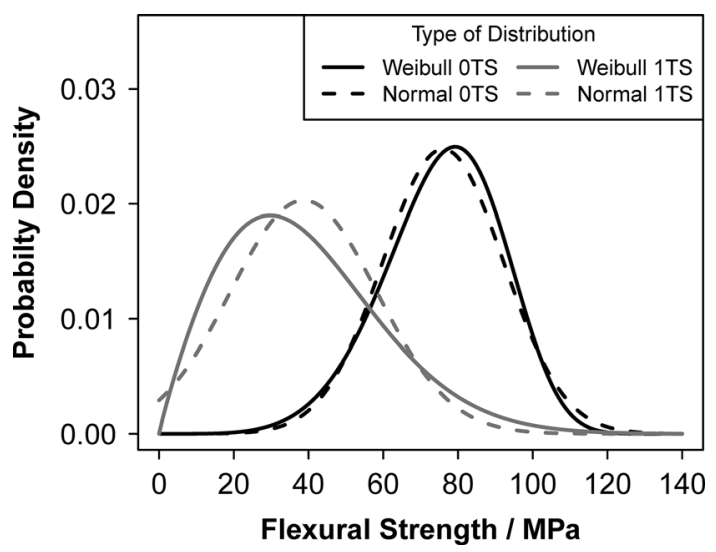

Fig. 5 Comparison of Weibull and Normal distribution of strength data prior (black) and after thermal shock (TS) from $1000{ }^{\circ} \mathrm{C}$ to room temperature (grey) determined by the two critical thermal shock gradients $\Delta T_{c}$ and $\Delta T_{\mathrm{c}_{\mathrm{c}}}\left(0<\Delta T<\Delta T_{\mathrm{c}}, \Delta \mathrm{T}=\Delta T_{\mathrm{c}}, \Delta T_{\mathrm{c}}<\Delta T<\Delta T_{\mathrm{c}}{ }_{\mathrm{c}}\right.$, $\left.\Delta \mathrm{T}>\Delta T^{\prime}{ }_{\mathrm{c}}\right)$. Only in the first stage $\left(\Delta T<\Delta T_{\mathrm{c}}\right)$, no change of the strength can be expected. At $\Delta T=\Delta T_{\mathrm{c}}$, fracture is initiated and thus strength decreases discontinuously (Ref 9). Therefore, it can be assumed that the characteristic strength is depending on the thermal shock gradient, if $\Delta T>\Delta T_{\mathrm{c}}$. In flame-sprayed alumina, Aneziris et al. (Ref 7), evinced a two-stage behaviour of the strength as function of $\Delta T$. Below $\Delta T=800 \mathrm{~K}$, the strength was approximately constant, before it degraded at higher $\Delta T$. Thus, a significant change of the characteristic strength $\sigma_{\mathrm{c}}$ can be expected for thermal shock gradients above $800 \mathrm{~K}$. However, a similar prediction for the Weibull modulus $m$ as a function of $\Delta T$ cannot be given, and therefore, the statistical measure $m$ has to be determined discretely in dependence on the thermal shock conditions and thus on the microstructural evolution.

\section{Conclusion}

Scope of the presented research was the statistical treatment of flexural strength data of thin flame-sprayed alumina coatings (free-standing) prior and after thermal shock by standard Weibull method. The obtained results allowed for the following conclusions:

- From the experimental aspects, the B3B-method allowed for the investigation of the flexural strength of thin flame-sprayed alumina coatings at room temperature without any pre-test selection. In perspective, the B3B-method also appears suitable for flexural testing at elevated temperatures.

- As expected, the scatter of flexural strength is higher for flame-sprayed alumina coatings when compared to the Weibull modulus e.g. reported for hot-isostatic pressed alumina.

- Thermal shock decreases the characteristic strength of flame-sprayed alumina according to the prediction and increases the scatter of flexural strength.

Table 4 Transformed (surface-related) characteristic strength $\sigma_{\mathrm{b}}$ for three- (3PB) and four-point-bending (4PB) prior to thermal shock including confidence band of $\sigma_{0 ; \mathrm{B} 3 \mathrm{~B}}$ and Weibull modulus $m$ (further acronyms: B3B-ball-on-three-balls testing, 1-lower, u-upper)

\begin{tabular}{lcccccr}
\hline B3B to 3PB & $m_{1}$ & $m$ & $m_{\mathrm{u}}$ & B3B to 4PB & $m_{1}$ & $m$ \\
\hline$\sigma_{0,1}, \mathrm{MPa}$ & 22.95 & 29.82 & 36.92 & $\sigma_{0,1}, \mathrm{MPa}$ & 19.13 & 25.11 \\
$\sigma_{0}, \mathrm{MPa}$ & 24.10 & 31.35 & 38.82 & $\sigma_{0}, \mathrm{MPa}$ & 20.11 & 26.40 \\
$\sigma_{0, \mathrm{u}}, \mathrm{MPa}$ & 25.36 & 32.98 & 40.84 & $\sigma_{0, \mathrm{u}}, \mathrm{MPa}$ & 21.16 & 27.78 \\
\hline
\end{tabular}

Effective surface areas for recalculation, brackets list values for lower and upper Weibull modulus

$S_{\text {eff }}=0.23 \mathrm{~mm}^{2}, S_{\mathrm{b} ; 3 \mathrm{~PB}}=126.12(121.58,131.31) \mathrm{mm}^{2}$, and $S_{\mathrm{b} ; 4 \mathrm{~PB}}=49.21(40.96,58.54) \mathrm{mm}^{2}$ 
- For a rough estimation of median strength and strength scatter in the as-sprayed state, arithmetic mean and standard deviation based on a normal distribution appear adequate. This however can not be applied for the flexural strength after thermal shock.

Further potential studies could address the impact of repetitive thermal shocks.

Acknowledgements The authors gratefully acknowledge funding by the German Research Foundation through the Collaborative Research Centre 920 "Multi-Functional Filters for Metal Melt Filtration-A Contribution towards Zero Defect Materials" (Project-ID 169148856), subprojects A01, C03, and S01.

Funding Open Access funding enabled and organized by Projekt DEAL.

Open Access This article is licensed under a Creative Commons Attribution 4.0 International License, which permits use, sharing, adaptation, distribution and reproduction in any medium or format, as long as you give appropriate credit to the original author(s) and the source, provide a link to the Creative Commons licence, and indicate if changes were made. The images or other third party material in this article are included in the article's Creative Commons licence, unless indicated otherwise in a credit line to the material. If material is not included in the article's Creative Commons licence and your intended use is not permitted by statutory regulation or exceeds the permitted use, you will need to obtain permission directly from the copyright holder. To view a copy of this licence, visit http://creativecommons. org/licenses/by/4.0/

\section{References}

1. A. Vardelle, C. Moreau, J. Akedo, H. Ashrafizadeh, C.C. Berndt, J.O. Berghaus, M. Boulos, J. Brogan, A.C. Bourtsalas, A. Dolatabadi, M. Dorfman, T.J. Eden, P. Fauchais, G. Fisher, F. Gaertner, M. Gindrat, R. Henne, M. Hyland, E. Irissou, E.H. Jordan, K.A. Khor, A. Killinger, Y.-C. Lau, C.-J. Li, L. Li, J. Longtin, N. Markocsan, P.J. Masset, J. Matejicek, G. Mauer, A. McDonald, J. Mostaghimi, S. Sampath, G. Schiller, K. Shinoda, M.F. Smith, A.A. Syed, N.J. Themelis, F.-L. Toma, J.P. Trelles, R. Vassen, and P. Vuoristo, The 2016 Thermal Spray Roadmap, J. Therm. Spray Technol., 2016, 25, p 1-65
2. T. Kratschmer and C.G. Aneziris, Amorphous Zones in Flame Sprayed Alumina-Titania-Zirconia Compounds, Ceram. Int., 2011, 37, p 181-188

3. P. Chagnon and P. Fauchais, Thermal Spraying of Ceramics, Ceram. Int., 1984, 10, p 119-131

4. R. McPherson, On the Formation of Thermally Sprayed Alumina Coatings, J. Mater. Sci., 1980, 15, p 3141-3149

5. D. Munz and T. Fett, Ceramics Mechanical Properties, Failure Behaviour, Materials Selection, Springer Ser. Mater. Sci., 2001, 36, p 25-26

6. T. Kratschmer, C.G. Aneziris, and P. Gruner, Mechanical Properties of Flame Sprayed Free-Standing Coatings, Ceram. Int., 2011, 37, p 2727-2735

7. C.G. Aneziris, P. Gehre, T. Kratschmer, and H. Berek, Thermal Shock Behavior of Flame-Sprayed Free-Standing Coatings Based on $\mathrm{Al}_{2} \mathrm{O}_{3}$ with $\mathrm{TiO}_{2}$ - and $\mathrm{ZrO}_{2}$-Additions, Int. J. Appl. Ceram. Technol., 2011, 8, p 953-964

8. M. Neumann, P. Gehre, J. Kuebler, N. Dadivanyan, H. Jelitto, G.A. Schneider, and C.G. Aneziris, Stable Crack Propagation in Free Standing Thermal Sprayed $\mathrm{Al}_{2} \mathrm{O}_{3}$ and $\mathrm{Al}_{2} \mathrm{O}_{3}-\mathrm{ZrO}_{2}-\mathrm{TiO}_{2}$ Coatings, Ceram. Int., 2019, 45, p 8761-8766

9. D.P.H. Hasselman, Unified Theory of Thermal Shock Fracture Initiation and Crack Propagation in Brittle Ceramics, J. Am. Ceram. Soc., 1969, 52, p 600-604

10. D.P.H. Hasselman, Strength Behaviour of Polycrystalline Alumina Subjected to Thermal Shock, J. Am. Ceram. Soc., 1970, 53, p $490-495$

11. C.U. Hardwicke and Y.C. Lau, Advances in Thermal Spray Coatings for Gas Turbines and Energy Generation: A Review, $J$. Therm. Spray Technol., 2013, 22(5), p 564-576

12. A. Börger, P. Supancic, and R. Danzer, The Ball on Three Balls Test for Strength Testing of Brittle Discs: Stress Distribution in the Disc, J. Eur. Ceram. Soc., 2002, 22, p 1425-1436

13. H. Zielke, A. Schmidt, M. Abendroth, M. Kuna, and C.G. Aneziris, Influence of the Specimen Manufacturing Process on the Strength of Carbon-Bonded Alumina $\left(\mathrm{Al}_{2} \mathrm{O}_{3}-\mathrm{C}\right)$, Adv. Eng. Mater., 2017, 19, p 1-7

14. G.D. Quinn, Standardized Rectangular Flexure Specimens, J. Am. Ceram. Soc., 2003, 10, p 508-510

15. M. Michálek, M. Michálková, G. Blugan, and J. Kuebler, Strength of Pure Alumina Ceramics Above $1 \mathrm{GPa}$, Ceram. Int., 2018, 44, p 3255-3260

16. P. Ostojic and C.C. Berndt, The Variability in Strength of Thermally Sprayed Coatings, Surf. Coat. Technol., 1988, 34, p 43-50

Publisher's Note Springer Nature remains neutral with regard to jurisdictional claims in published maps and institutional affiliations. 